\title{
Measuring Wine Industry Efficiency with Wine Industry Network Evaluation Model (WINE-Model)
} Mario Arturo Ruiz Estrada', Donghyun Park², and Anthony T. H. Chin ${ }^{3}$

ABSTRACT

We propose a group of indicators for the analysis of wine industry performance. We present a new model that analyzes the direct impact of wine industry productivity rate $\left(\Pi^{*}\right)$, the wine industry performance rate $(\Delta \Pi)$, the wine cargo expansion rate $(\Delta \Pi)$, and the wine industry technological change adaptability rate $(\varphi)$ on wine industry network efficiency (WINE-Index). This new model, "The Wine Industry Network Evaluation Model (WINE-Model)" is intended to offer policy makers and researchers an additional analytical tool to study the impact of dynamic changes such as international trade trends and technological shocks on wine industry performance from a new perspective. The WINE-Model can be applied to the study of any wine industry and is not constrained by geographical area or development stage of the industry. The WINE-Model is thus simple, flexible, and versatile. We apply the model to the wine industries of Spain, Italy, France, Chile, Argentina, and Greece. Perhaps the WINE-Model's biggest strength is its ability to capture and measure industry performance from a dynamic perspective.

KEY WORDS: $\quad$ Wine industry performance, productivity, dynamics, technology, growth

JEL Classification: B41.

University of Malaya, Malaysia

${ }^{2}$ Asian Development Bank, Phillipines

${ }^{3}$ National University of Singapore, Singapore

\section{Introduction}

Studies of wine industry performance have largely focused on derivation of key performance indicators and efficiency indicators. However, no two wine industries have similar operating environments, managerial competency, innovation, institutional set up, and government support. As such, comparing the wine industry performance of different countries would not be meaningful without greater transparency of data. Furthermore, the wine industry forms part of dynamic global market undergoing constant supply and demand shocks. The dynamic nature and mobility of

Correspondence concerning this article should be addressed to: Mario Arturo Ruiz Estrada, University of Malaya, 50603 Kuala Lumpur, Malaysia.E-mail: marioruiz@um.edu.my production centers, from procurement of primary and intermediate inputs to production to distribution of final products, is constantly affecting the costs of wine producers and competition between them.

The wine industry does not exist within a vacuum. Therefore, measurement of wine industry performance should not occur in a vacuum. However, fundamental information such as efficiency and production cost rates is shrouded under commercial confidentiality. A wine industry may be efficient but not effective. Being effective is to serve the right markets at the right time, which efficiency indicators may fail to capture. That is, effectiveness is not just about efficiency alone. For example, easing access into wine industry when new technology is not readily available may affect effectiveness more than efficiency. Therefore, evaluating wine 
industry requires clear reference points.

Doing so allows wine industry operators an insight into what customers are looking for and constantly improve services to wine customers in different markets around the world. Producers, suppliers, sellers, shipping lines, freight companies are the key global wine supply chain players who influence warehousing costs, reliability, and safety of wines. Shipping lines focus on load factors, congestion of the wine industry, costs of operation, and environmental taxes.

The global wine supply chain players are concerned with multi-modal connectivity to the wine industry, access and egress times from the wine industry to custom procedures. Time sensitive wine cargo requires quick turnaround times, which only some wine industries are able to deliver. Wine industry effectiveness and performance is a complex issue subject to perception and subjective preferences but it is best measured from user perspectives which require the wine industry to reconcile production, externalities, productivity, service gaps, and different priorities. We offer an alternative approach to the study of wine industry performance measurement, an approach more suitable for a dynamic environment.

The rest of this paper is organized as follows. We first summarize the existing literature, and then we introduce the Wine Industry Network Evaluation model (WINE-Model). We apply the model to the wine industries of Spain, Italy, France, Greece, Chile, and Argentina, and report and discuss the results. We then conclude the paper.

\section{Literature Review}

The analysis of the wine industry performance has taken both quantitative and qualitative approaches. Here we propose the Wine Industry Performance Evaluation Model (WINE-Model) as an alternative analytical approach in the study of wine industry, specifically for measuring productivity. We follow the interesting research works of Balakrishnan and Pushpangadan (1994), Fernandez Olmos (2010), Garcia, F., Marchetta, M., Camargo, M., Morel, L., and Forradellas, R. (2012), Crozet, M., Head, K., and Mayer, T. (2012), and Mariani, A., Pomarici, E., and Boatto, V. (2012). However, while the four research papers provide different points of view about the wine industry issues from qualitative and quantitative perspectives, we recommend the use of a large number of variables in constructing the wine industry network evaluation model (WINE-Model).

Hence, the included variables will have the same level of importance and integrated into the same indicator and graphical space. Moreover, we try to capture many variables present in the dynamic interplay of wine industry productivity and factors such as light and heavy machinery industry, biotechnology industry, and other industries related to wine production. However, the wine industry network efficiency (WINE-Index) singles out a small subset of such variables, divides them into exogenous and endogenous variables, and assumes that everything other than those variables is exogenous.

Hence, we look at the problem from a more integrative analytical standpoint that considers the dynamic co-movement of all relevant variables. This co-movement is then represented in a multidimensional graph and subsequently, we compute a set of indices that allow policy makers to estimate wine industry network efficiency (WINE-Index) as an annual percentage of a country's wine industry efficiency output, which in turn, can be computed from the country's wine competitiveness estimates. In addition, the wine industry performance rate $(\Delta \Pi)$ is based on a set of raw input data that are collected annually from the national wine production records, data which are subsequently transformed into an alternative set of variables.

Nine wine industry performance indicators are included in the model: (i) Training: Number of training sessions annually, (ii) physical condition: basic medical annual checkup per worker, (iii) years of experience: average years of working experience among all staff, (iv) ratio of local to foreign workers: we compare the percentage between local and foreign workers, (v) technological management: basic use of technology, (vi) incentives programs: allowance and commissions, (vii) salaries skills: time and amount of money, (viii) management system: centralized or des-centralized management systems, and (ix) environmental changes: climate changes, measured by temperature and rain levels.

These variables, observed annually, are then transformed into annual growth rates of change. From the mathematical perspective, wine industry 
performance rate $(\Delta \Pi)$ is not a simple relationship between two variables (such as the endogenous variable and the exogenous variable) that are fixed at a specific time and space. Hence, the wine industry performance rate $(\Delta \Pi)$ requires a multi-variable analytical framework, where no variable is isolated in the mathematical and graphical modeling.

A multi-dimensional graphical modeling is used in the construction of the area of coverage from the WINE-Index (ACW). The multi-dimensional graphical modeling is an alternative graphical approach to observe the behavior of a large number of variables that move within the same graphical space. This type of modeling requires simultaneous application of a multi-dimensional graphical modeling conceptualized under "Econographicology" (Ruiz Estrada and Park, 2018). The multi-dimensional graphical modeling enables observation of all changes in different variables in the same graphical space. All these variables are changing constantly over time in different parts within the same space. The application of the multi-dimensional graphical modeling enables us to evaluate the performance of any wine industry from a multi-dimensional perspective.

The construction of the wine industry network efficiency (WINE-Index) varies from one country to another. It varies according to staple wine preferences, wine market size, geographical location, and probability of climate change, and finally, the statistical resources available in the country. In the construction of the wine industry network efficiency (WINEIndex), the implicit assumption is that it is impossible to predict or forecast any externality such as economic crisis or climate changes with accuracy based on a stable relationship between a single exogenous variable and a single endogenous variable.

We take view that the absence of non-quantitative variables can compromise measurement of wine industry performance. Therefore, we suggest that a wine industry performance model should take into consideration a wide range of factors, including unforeseen ones. These include factors such as climate changes, environmental factors, financial crisis, globalization, smuggling, and monopoly power. Such comprehensive analysis will allow for concrete policies that improve wine industry performance in the long run. However, all these factors are assumed to undergo steady transformation(s) through different historical stages of wine industry development.

We deploy the WINE-Model here to analyze how wine industry productivity rate, wine industry performance rate, wine cargo expansion rate, and wine industry technological change adaptability rate can affect directly WINE-Index performance, regardless of the wine industry size. The model allows us to quantify and analyze the WINE-Index rate. We employ a mathematical and graphs to analyze the wine industry performance and suggest a set of new indicators to evaluate the wine industry performance. Its advantage is flexible adaptability in analyzing performance without any restrictions. The model will test two following hypotheses:

1. Wine industry productivity rate performance is directly and simultaneously connected to the efficient coordination of wine market openness, wine industry performance level, wine cargo expansion level, and wine industry adaptability to technological changes;

2. The profit of any wine industry is dependent on how fast, smooth and flexible it is in utilizing human capital in adapting to new technological changes in the wine industry.

\section{The WINE-Model Framework}

The WINE-Model is involving on a series of steps in its application to study the wine industry performance:

Step-1 Derivation of the Total Volume of Wine Production Annually ( $\Psi \mathrm{T})$

Step-2 The Share of Any Wine Industry into the Total National Wine Production $(\lambda)$

Step-3 Derivation of the Wine Market Openness Rate (Opt)

Step-4 Derivation of the Wine Market Openness Rate (Opt)

Step-5 Calculation of the Wine Cargo Expansion Rate $(\Delta \varsigma)$

Step-6 Analysis of the Wine Industry Productivity Rate $\left(\Pi^{*}\right)$

Step-7 Measurement of the Wine Market Openness Rate/Wine Industry/Productivity Rate $\left(\mathrm{Op}: \Pi^{*}\right)$ Sensitivity Analysis

Step-8 Derivation of the Wine Industry Network Efficiency Index (WINE-Index)

Step-9 Plotting of Area of Coverage from the WINE- 
Index (ACW)

\subsection{Step-1: Derivation of the Total Volume of Wine Production Annually $\left(\Delta \Psi_{T}\right)$}

Initially, the total volume of wine industry production annually $\left(\Delta \Psi_{T}\right)$ which is equal to the total sum of the same wine annual production in the present year $\left(\Sigma \Psi_{\mathrm{o}}\right)$ minus the total sum of wine production of the past year $\left(\sum \Psi_{\mathrm{n}-1}\right)$ divided by the total sum of the wine production of the past year $\left(\Sigma \Psi_{n-1}\right)$.

$$
\Delta \Psi_{\mathrm{T}}=\frac{\sum \Psi_{\mathrm{T}+1}-\Sigma \Psi_{\mathrm{n}-1}}{\Sigma \Psi_{\mathrm{n}-1}} \times 100 \%
$$

The results of $\Delta \Psi T$ reflect two possible scenarios:

(i) If $\Delta \Psi_{\mathrm{T}}$ rate is high, then the wine industry experiences strong performance

(ii) If $\Delta \Psi_{T}$ rate is low, then the wine industry experiences weak performance.

\subsection{Step-2: The Share of Any Wine Industry into the Total National Wine Production $(\Delta \lambda)$}

The second indicator in our model is called "The share of any wine industry into the total national wine production $(\Delta \lambda)$ ". Additionally, we identified that the total volume of wine from a specific industry by using the total annual output of wine production growth rate $(\Delta \Psi T)$; the total volume of wine is fixed under the total sum of liters of wine is produced by any wine industry with; and the national wine production is represented by the total national output of wine growth rate $(\Delta \Sigma \mathrm{L}, \mathrm{T})$ respectively. This indicator is responsible to evaluate how much a wine industry contributes into the national wine production. The calculation of is equal to:

$\lambda=\Delta \Psi_{\mathrm{T}} / \Delta \Sigma \mathrm{L}_{\mathrm{T}} * 100 \%$

Therefore, our marginal share of any wine industry into the total national wine production is fixed in our equation 3.

$$
\Delta \lambda=\partial \mathrm{d} \Delta \Psi_{\mathrm{T}} / \partial \mathrm{d} \Delta \Sigma \mathrm{L}_{\mathrm{T}}
$$

\subsection{Step-3: Derivation of the Wine Market Open- ness Rate (Opt)}

In case of the wine industry openness rate formula is equal to:

$\mathrm{Opt}=\mathrm{WX}_{\text {real prices }}+\mathrm{WM}_{\text {real prices }} / \mathrm{GDP}_{\text {real prices }}$

In the case of the wine market openness rate, this indicator will show the type of international trade policy any country carries such as the wine industry substitution industrialization (protectionism) and the wine industry oriented (free trade) (Ruiz Estrada and Yap, 2006). Hence, we are evaluating how a wine market is open to the rest of the world. The Opt is equal to the sum of wine exports in real prices $\left(\mathrm{WX}_{\text {real prices }}\right)$ plus imports of wine in real prices $\left(\mathrm{WM}_{\text {real prices }}\right)$ divided by the GDP in real prices (see Expression 4).

Analysis of OpT Results:

(i) If Opt is high, then the country experiences strong openness growth

(ii) If Opt is low, then the country experiences weak openness growth.

\subsection{Step-4 Measurement of the Technological Changes Adaptability Rate $(\phi)$}

Basically, we use two main variables to calculate the technological changes adaptability rate $(\phi)$. The technological changes adaptability rate $(\phi)$ is computed by dividing the initial investment in technology per $\mathrm{km} 2$ ( $\mathrm{T}$ ) by the total plantation extension by $\mathrm{km} 2$ in the same geographical space in a period of one year (P). Finally, we generate the natural logarithm to calculate the final technological changes adaptability rate $(\phi)$ that is expressed in the Expression 5 .

$\phi=\operatorname{Ln}(\mathrm{T} / \mathrm{P})$

\subsection{Step-5 Calculation of the Wine Cargo Expan- sion Rate $(\Delta \mathrm{\varsigma})$}

We do so by applying the wine cargo expansion rate $(\Delta \varsigma)$, which is equal to the total sum of the wine cargo in the present year $\left(\Sigma \varsigma_{0}\right)$ and then subtracted from the total sum of the wine cargo in the past year $\left(\Sigma \varsigma_{n-1}\right)$ and then divided by the total sum of the same type of wine cargo in the past year $\left(\Sigma \varsigma_{n-1}\right)$ (see Expression 6).

$\Delta \varsigma=\left[\Sigma \varsigma_{\mathrm{o}}-\Sigma \varsigma_{\mathrm{n}-1}\right] / \Sigma \varsigma_{\mathrm{n}-1}$ 


\subsection{Step-6: Analysis of the Wine Industry Pro- ductivity Rate $\left(\Pi^{*}\right)$}

The wine industry productivity rate $\left(\Pi^{*}\right)$ is based on the uses of three co-factors that we like to applied multi-partial differentiation simultaneously (see Expression 7 ). The variables are using to measure the $\Pi^{*}$ is based on the wine labor demand growth rate $(\Delta \alpha)$; the wine industry equipment and machinery demand growth rate $(\Delta \beta)=$ ratio of investment in machines and tools growth rate; the ratio of wine capacity of storage growth rate $(\Delta \theta)=$ ratio of wine storage space per liters; the ratio of wine plantation growth rate $(\Omega)=$ wine plantation by $\mathrm{Km} 2$; the wine logistic services growth rate $(\Delta \gamma)=$ transport and telecommunications firms supply; The construction of the wine industry productivity rate $\left(\Pi^{*}\right)$ is to evaluate the fast changes and adaptability of labor and capital in the process of the wine industry growth expansion (see Figure 1). Finally, the wine industry productivity rate (see Expression 7).

$\Pi^{*} \equiv\left(\frac{\partial(\Delta \alpha)(\Delta \beta)(\Delta \theta)(\Delta y)}{\partial(\Delta \Omega)}\right)$
To prove the wine industry productivity rate $\left(\Pi^{\star}\right)$, we will propose a mathematical framework to the wine industry. However, we are going to applied statistical data to calculate the wine industry productivity rate $\left(\Pi^{\star}\right)$ on different major wine producers. Hence, the main idea is to analyze the wine industry productivity rate $\left(\Pi^{*}\right)$ behavior by parts under the application of a large number of partial derivatives see bellows.

The wine industry labor demand contribution in productivity $(\xi \alpha)$ :

$\xi_{\alpha}=\left[\underline{\pi_{i}(\partial \alpha / \partial \beta)}\right]_{0} / \Omega_{0} \ldots\left[\underline{\pi_{i}(\partial \alpha / \partial \beta)}\right]_{\infty} / \Omega_{\infty}\left\{\alpha, \beta, \Omega \Rightarrow \mathrm{R}_{+} \forall \neq 0\right\}(8)$

The wine industry equipment and machinery contribution in productivity $(\xi \beta)$ :

$\xi_{\beta}=\left[\underline{\pi_{i}(\hat{\partial} \beta / \partial \alpha)}\right]_{0} / \Omega_{0} \ldots\left[\underline{\pi_{i}(\partial \beta / \partial \alpha)}\right]_{\infty} / \Omega_{\infty}\left\{\alpha, \beta, \Omega \Rightarrow R_{+} \forall \neq 0\right\}$

Thus, we prove that the profit $(\pi)$ is represented by:

$\Pi=\left(\xi_{\alpha}=\xi_{\beta}\right)$

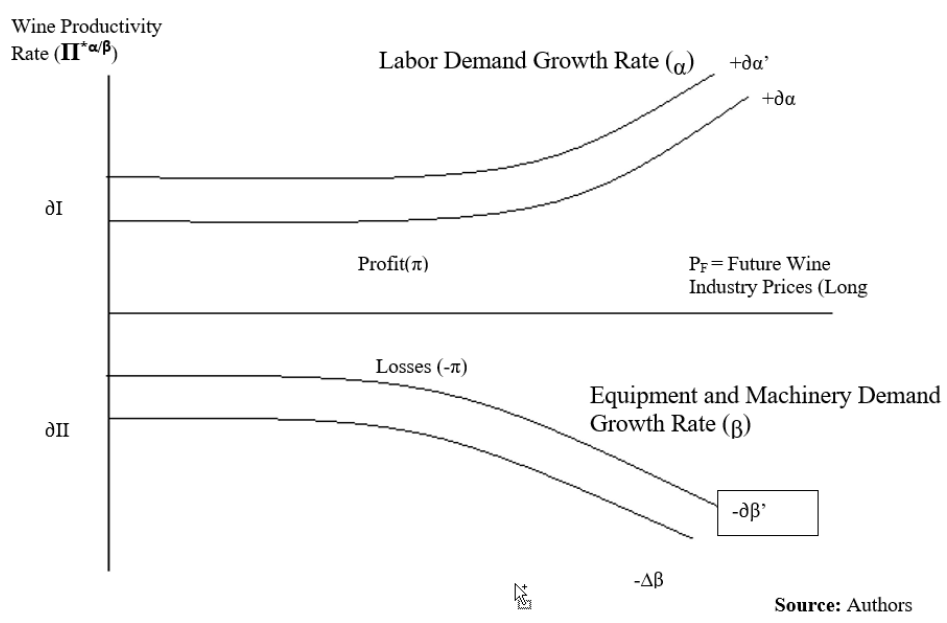

Figure 1. Wine industry productivity rate. 
Finally, we can prove that the profit and losses of any wine industry is strongly related about the optimum combination between labor $(\xi \alpha)$ and capital $(\xi \beta)$. It is possible to be observed in the figure 2 that in the initial state of any wine industry the profit is directly connected to the high intensity of capital $(\xi \beta)$ at the short run, but in the long run the profit is going to be directly connected to the intensive uses of labor $(\xi \alpha)$.

\subsection{Step-7: Measurement of the Wine Market Openness Rate and the Wine Industry Productiv- ity Rate $\left(\mathrm{Opt} / \Pi^{\star}\right)$ Sensitivity Analysis}

This indicator measures the vulnerability of any wine industry performance under the analysis of the wine market openness rate (Opt) and wine industry productivity rate $\left(\Pi^{*}\right)$ simultaneously. The main objective is to compares the trend of wine market openness and productivity behavior together.

$$
\mathrm{Opt} / \Pi^{*}=\mathrm{Opt}: \Pi^{*}
$$

\subsubsection{Results of $\left(\mathrm{Opt}: \Pi^{\star}\right)$ Sensitivity Analysis}

The (Op:T) sensitivity analysis reflects several possible scenarios:

(i) If $\boldsymbol{\Delta}$ Opt: $\boldsymbol{\Delta} \Pi^{*}$ then the wine industry capability has good performance (ii) If $\boldsymbol{\nabla}$ Opt: $\boldsymbol{\nabla}_{\Pi^{*}}$ then the wine industry capability has poor performance

(iii)If $\boldsymbol{\Delta}$ Opt: $\boldsymbol{\nabla}^{\star}$ then the wine industry capability has inconsistent performance

(iv) If $\boldsymbol{\nabla}$ Opt: $\boldsymbol{\Delta} \Pi^{*}$ then the wine industry capability has inconsistent performance

(Opt): Wine Industry Openness

$\left(\Pi^{\star}\right)$ : Wine Industry Productivity

$\boldsymbol{\Delta}$ : increase

$\boldsymbol{\nabla}$ : decrease

\subsection{Derivation of the Wine Industry Network Ef- ficiency (WINE-Index)}

In the case of the WINE-index is based on a several number of variables such as (i) Training: Number of training sessions annually, (ii) physical condition: basic medical annual checkup per worker, (iii) years of experience: average years of working experiences among all staff, (iv) ratio of local and foreign workers: we compare the percentage between local and foreign workers, (v) technological management: basic uses of technology in the working place of each worker, (vi) incentives programs: allowance and commissions, (vii) salaries skills: time and amount of money, (viii) management system: centralized or des-centralized management systems, (ix) environmental changes: climate changes in the temperature and rain levels. The first step to developing the wine industry network efficiency

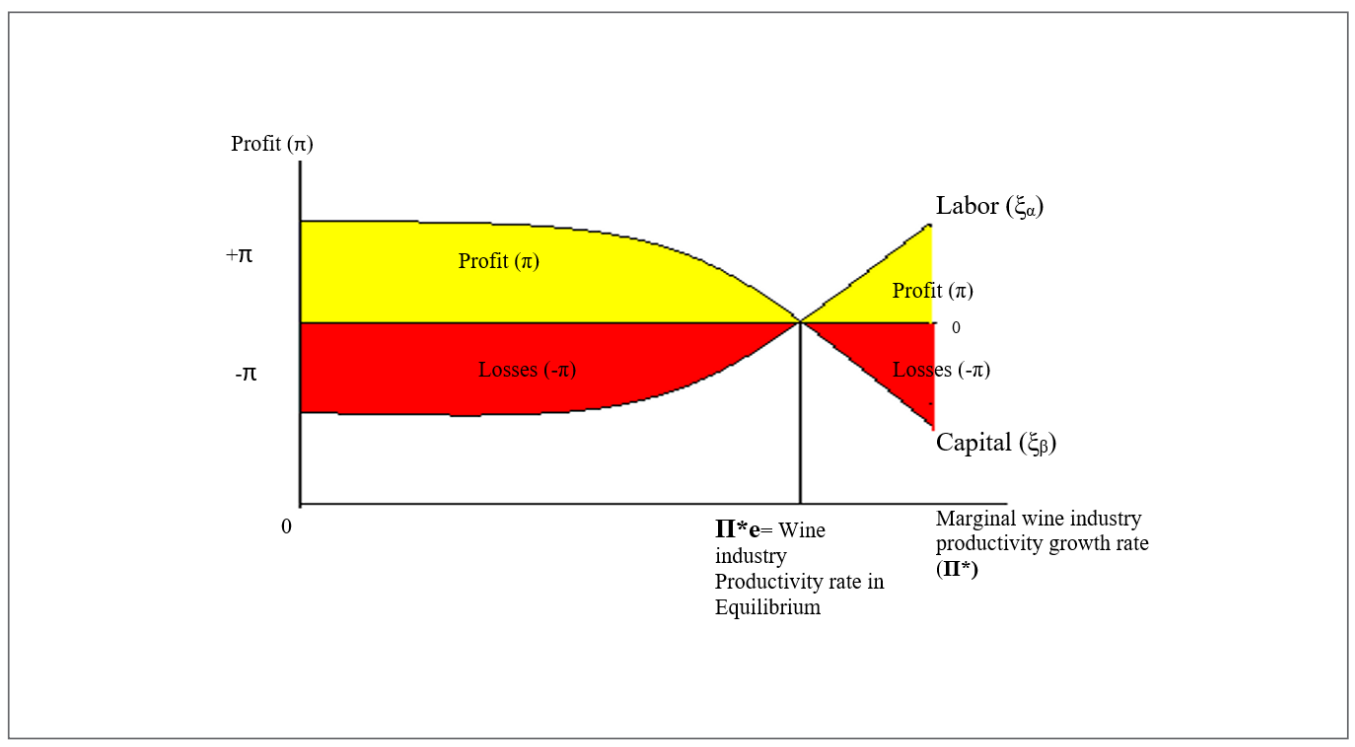

Figure 2. Wine industry profit analysis. 
(WINE-Index) starts by building the main-variable of the wine industry performance by using Expression 12 . Subsequently, we compare the data obtained a year before (To) to the current data (Tf).

$$
\Delta \mathrm{X}_{\mathrm{ij}}=\left[\mathrm{X}_{\mathrm{ij}(\mathrm{Tf})}-\mathrm{X}_{\mathrm{ij}(\mathrm{To})}\right] / \mathrm{X}_{\mathrm{ij}(\mathrm{To})}
$$

The second step is the construction of the nine wine output performance main-variables as expressed in Expression 13 .

$$
\begin{aligned}
\Delta X_{11} & =\left[\mathrm{X}_{11(\mathrm{Tf})}-\mathrm{X}_{11(\mathrm{To})}\right] / \mathrm{X}_{11(\mathrm{To})} \\
\Delta \mathrm{X}_{12} & =\left[\mathrm{X}_{12(\mathrm{Tf})}-\mathrm{X}_{12(\mathrm{To})}\right] / \mathrm{X}_{12(\mathrm{To})} \\
\Delta \mathrm{X}_{13} & =\left[\mathrm{X}_{13(\mathrm{Tf})}-\mathrm{X}_{13(\mathrm{To})}\right] / \mathrm{X}_{13(\mathrm{To})} \\
\Delta \mathrm{X}_{21} & =\left[\mathrm{X}_{21(\mathrm{Tf})}-\mathrm{X}_{21(\mathrm{To})}\right] / \mathrm{X}_{11(\mathrm{To})} \\
\Delta \mathrm{X}_{22} & =\left[\mathrm{X}_{22(\mathrm{Tf})}-\mathrm{X}_{22(\mathrm{To})}\right] / \mathrm{X}_{22(\mathrm{To})} \\
\Delta \mathrm{X}_{23} & =\left[\mathrm{X}_{23(\mathrm{Tf})}-\mathrm{X}_{23(\mathrm{To})}\right] / \mathrm{X}_{13(\mathrm{To})} \\
\Delta \mathrm{X}_{31} & =\left[\mathrm{X}_{31(\mathrm{Tf})}-\mathrm{X}_{31(\mathrm{To})}\right] / \mathrm{X}_{31(\mathrm{To})} \\
\Delta \mathrm{X}_{32} & =\left[\mathrm{X}_{32(\mathrm{Tf})}-\mathrm{X}_{32(\mathrm{To})}\right] / \mathrm{X}_{32(\mathrm{To})} \\
\Delta \mathrm{X}_{33} & =\left[\mathrm{X}_{33(\mathrm{Tf})}-\mathrm{X}_{33(\mathrm{To})}\right] / \mathrm{X}_{33(\mathrm{To})}
\end{aligned}
$$

The final calculation of the wine industry performance rate $(\Delta \Pi)$ is based on Expression 14. We multiply each main-variable of the wine output productivity performance by a constant. This constant is equal to (0.11111) because it is divided by $1 / 9$ (number of main-variables). Hence, the main reason behind the application of the constant is to obtain a final result of 1 (equal to $100 \%$ ).

$\Delta \Pi=\sum\left[\left(\Delta \mathrm{X}_{11}\right) * \mathrm{~K}+\left(\Delta \mathrm{X}_{12}\right) * \mathrm{~K}+\left(\Delta \mathrm{X}_{13}\right) * \mathrm{~K}\right.$

$+\left(\Delta \mathrm{X}_{21}\right) * \mathrm{~K}+\left(\Delta \mathrm{X}_{22}\right) * \mathrm{~K}+\left(\Delta \mathrm{X}_{23}\right) * \mathrm{~K}$

$\left.+\left(\Delta \mathrm{X}_{31}\right) * \mathrm{~K}+\left(\Delta \mathrm{X}_{32}\right) * \mathrm{~K}+\left(\Delta \mathrm{X}_{33}\right) * \mathrm{~K}\right]=1$

In addition, the wine industry performance rate $(\Delta \Pi)$ can be less or equal to 1 but never greater than 1 as expressed in Expression 15.

$\Delta \Pi \leq 1$

This research contends that the wine industry performance rate $(\Delta \Pi)$ cannot be represented by a matrix. This is so given the arbitrariness of the arrangement of elements of the matrix where its determinant depends on this arrangement. Hence, the wine industry performance rate $(\Delta \Pi)$ is not invariant to this ordering and changing the positions of the nine elements arbitrarily, changes the value of this determinant. Hence, this re- search observed that it is a fundamental shortfall of methods that use to use matrix to find $\Delta \Pi$.

Furthermore, since there are no functional relationships postulated, the matrixes of the nine elements are simply the nine elements arranged as a matrix to be plotted on the area of coverage in WINEIndex. If these multidimensional data are represented on the n-parallel vertical lines that are equidistant from the center where another parallel vertical line is drawn on which the quota is plotted, then we have another result quite different from the original $\Delta \Pi$-result. Therefore, we propose the use of Expression 30 to calculate the wine industry performance rate $(\Delta \Pi)$. It is suggested that the nine main-variables of the wine output productivity performance in our model are (i) Training: Number of training sessions annually, (ii) physical condition: basic medical annual checkup per worker, (iii) years of experience: average years of working experiences among all staff, (iv) ratio of local and foreign workers: we compare the percentage between local and foreign workers, (v) technological management: basic uses of technology in the working place of each worker, (vi) incentives programs: allowance and commissions, (vii) salaries skills: time and amount of money, (viii) management system: centralized or des-centralized management systems, (ix) environmental changes: climate changes in the temperature and rain levels. Each main-variable of the wine industry performance rate $(\Delta \Pi)$ is based on an annual growth rate - Each variable of performance should be based on the uses of annual growth rates (see Expression 12 and 13).

Third step in the WINE-Index is the construction of the $\Omega$-Coefficient. To do so, we need to multiply the wine industry performance rate $(\Delta \Pi)$; cargo expansion rate $(\Delta \varsigma)$; the technological changes adaptability rate $(\phi)$; the wine industry productivity rate $\left(\Pi^{\star}\right)$ together (see Expression 16) gives the product.

$$
\Omega \text {-Coefficient }=\left[(\Delta \Pi)(\Delta \varsigma)(\phi)\left(\Pi^{*}\right)\right]
$$

The final step is to measure the wine industry network efficiency (WINE-Index) final amount. The WINEindex final amount is equal to apply the square root of four on the final multiplication of $\Omega$-Coefficient. The final result is then multiplied by $100 \%$ (see Expression 17). 
WINE-Index $=4 \sqrt{\Omega \text {-Coefficient }} * 100 \%$

The economic justification of the wine industry network efficiency (WINE-Index) final amount is that this single index can facilitate policy choices (Ruiz Estrada, 2011) drawn from the calculation and evaluation of the wine industry performance standards of any wine producer needs to produce and store to keep a competitive position.

\subsection{Step-9: Plotting of Area of Coverage from the WINE-Index}

The Diamond Coordinate Space (Ruiz Estrada, 2011) presents a general idea about the current wine industry development based on a new concept of graphic representation (see Figure 3). This new concept of graphic representation consists of six axes, each of which has only positive values. In the case of this research, the value in four of the axes is represented by the degree of the wine industry growth (the wine industry performance rate, the wine industry productivity rate, cargo expansion rate, technological changes adaptability rate). These indexes are independent variables. There can be joined together to create a general area. This general area is called "area of coverage of the wine industry efficiency (ACW)".

This area shows the dimension of the wine industry growth performance from a general perspective. For comparison purposes, the wine industry network efficiency (WINE-Index) can be applied to different years for one wine industry or two wine industries. The analysis of the WINE-Index is based on the comparison of two periods. In the case of this research study, two periods (i.e. first period and second period) are compared. The total ACW may present three possible scenarios, namely:

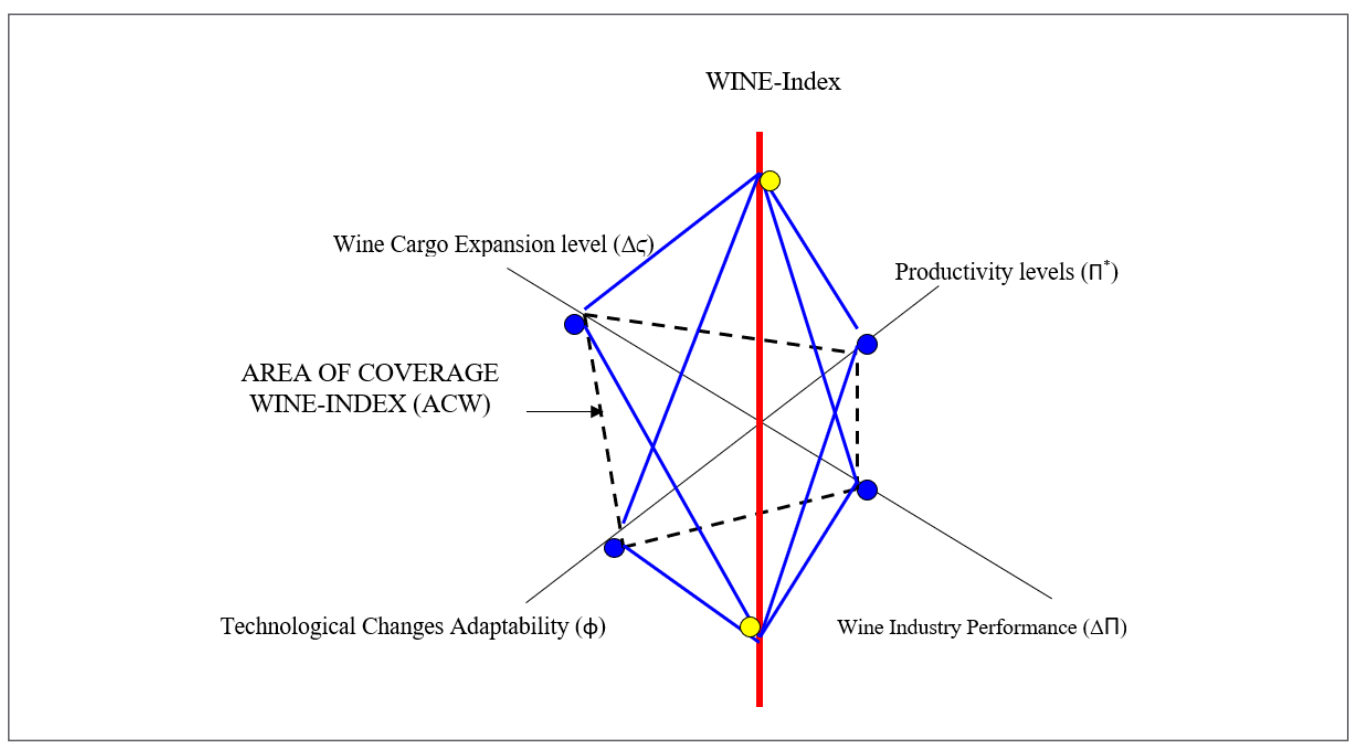

Figure 3. The area of coverage from WINE-index.

Source: Hellenic Republic Ministry of Rural Development and Food (2017); Ministerio de Agricultura Española (2017); Ministero Delle Politiche Agricole Alimentari e Forestali (2017); Ministere de'l Agriculture de'l Agroalimentaire (2017); Ministro de Agricultura Chileno (2017); Ministerio de Agricultura, Ganaderia, y Pesca Argentino (2017); The Wine Institute (2017); World Trade Organization (2017). 
(a) Expansion (ACW' first period < ACW" second period)

(b) Stagnation (ACW' first period = ACW" second period)

(c) Contraction (ACW' first period > ACW" second period)

The fifth and sixth axes are represented by the dependent variables $\mathrm{Y}^{\star}$ (WINE-Index). They are positioned in the center of the graph which is the meeting point of the other four axes.

\section{WINE-Model and the Perfor- mance of selected Major Wine Pro- ducers}

The WINE-Model was applied initially to six large world producers of wine, namely Spain, Italy, France, Greece, Chile, and Argentina r(see Table
1). The period of study is between 1970 and 2010, which was selected to evaluate if there is a strong linkage between wine industry productivity growth rate and four main variables of interest. The four variables are wine industry performance rate, wine industry productivity rate, wine cargo expansion rate, and adaptability of wine industry to technological change. The results show that wine industry productivity rate is directly dependent on efficient coordination of wine industry performance rate, wine industry productivity rate, wine cargo expansion rate, and adaptability rate to technological change. According to the WINE-Model results, France enjoys the highest wine industry productivity rate (see Table 1 and Figure 4), followed by Spain and Italy (see Table 1 and Figure 6), and Chile, Argentina, and Greece, which placed last. Greece shows a weaker wine industry performance rate, accompanied by slow wine cargo expansion, a

Table 1. WINE-Model Results

\begin{tabular}{|c|c|c|c|c|c|}
\hline Wine industry & $\begin{array}{l}\text { The Wine Industry } \\
\text { Performance Rate } \\
(\Delta \Pi)\end{array}$ & $\begin{array}{l}\text { The Wine Industry } \\
\text { Productivity Rate } \\
\qquad\left(\Pi^{*}\right)\end{array}$ & $\begin{array}{c}\text { The Wine Cargo } \\
\text { Expansion Rate } \\
(\Delta \varsigma)\end{array}$ & $\begin{array}{c}\text { The Wine Industry } \\
\text { Technological } \\
\text { Changes Adapt- } \\
\text { ability Rate }(\phi)\end{array}$ & WINE-Index \\
\hline Spain & 1.00 & 0.95 & 0.93 & 0.92 & 0.95 \\
\hline Italy & 1.00 & 0.96 & 0.90 & 0.91 & 0.94 \\
\hline France & 1.00 & 0.93 & 0.99 & 0.96 & 0.97 \\
\hline Chile & 0.83 & 0.91 & 0.91 & 0.93 & 0.89 \\
\hline Argentina & 0.78 & 0.86 & 0.91 & 0.88 & 0.86 \\
\hline Greece & 0.69 & 0.41 & 0.57 & 0.55 & 0.55 \\
\hline
\end{tabular}

Source: Hellenic Republic Ministry of Rural Development and Food (2017); Ministerio de Agricultura Española (2017); Ministero Delle Politiche Agricole Alimentari e Forestali (2017); Ministere de'l Agriculture de'l Agroalimentaire (2017); Ministro de Agricultura Chileno (2017); Ministerio de Agricultura, Ganaderia, y Pesca Argentino (2017); The Wine Institute (2017); World Trade Organization (2017). 
low wine industry productivity rate, and slow adaptability rate to technological change (see Table 1 and Figure 5).

In addition, the WINE-Model was evaluated by using the Wolfram Mathematica version 7. To do so, we input all equations together with a large amount of data. The main objective of running the WINE-Model with Mathematica Version 7 is to observe mathematically and graphically how the wine industry productivity rate evolution is directly and simultaneously connected to the efficient coordination of wine industry performance rate $(\Delta \Pi)$, wine industry productivity rate $\left(\Pi^{*}\right)$, wine cargo expansion rate $(\Delta \varsigma)$, and adaptability of wine industry to technological changes $(\phi)$. At the same time, the profit of any wine industry depends on how quickly, smoothly, and flexibly its human capital adapts to new technological shocks and changes.

\section{Discussion and Policy Implications}

The econometric analysis of the WINE-Model is based on the evaluation of WINE-Index on Spain, Italy, France, Greece, Chile, and Argentina. The empirical model is specified as follows:

$$
\delta=\beta_{\mathrm{o}}+\beta_{1} \Delta \Pi+\beta_{2} \Delta \zeta+\beta_{3} \phi+\beta_{4} \Pi^{*}+\mathrm{e}_{\mathrm{i}}
$$

Two main variables play an important role in the analysis of the WINE-Index and they are; the wine industry performance rate $(\Delta \Pi)$; wine cargo expansion rate $(\Delta \varsigma)$; the technological changes adaptability rate $(\phi)$; the wine industry productivity rate $\left(\Pi^{*}\right)$. WINE-Index is constructed based on GARCH $(1,1)$ specification in a simple equation in which the logarithm in the wine industry performance rate $(\Delta \Pi)$ follows an $\mathrm{AR}(1)$ process. In Equation 18, one could observe the adequate dynamics to form a restricted error-correction model. Whereas in the case of a longrun model for WINE-Index can be obtained from the reduced form solution when all dynamic factors of the predictor variable are set at zero.

The econometric analysis in Table 2 helps to probe that the fast expansion of the WINE-Index is directly affected by the wine industry performance rate $(\Delta \Pi)$; the wine cargo expansion rate $(\Delta \varsigma)$; the technological changes adaptability rate $(\phi)$; the wine industry productivity rate $\left(\Pi^{*}\right)$ directly. Hence, the WINE-

Table 2. The Impact of $\Omega$-Coefficient on WINE-Index

\begin{tabular}{llc}
\hline & Year 1970 & Year 2010 \\
\hline Intercept & $\begin{array}{l}0.03371^{*} \\
(0.00115)\end{array}$ & $0.0425^{* * *}(0.00119)$ \\
$\Omega$ - Coefficient & $\begin{array}{l}0.44750^{* *} \\
(0.0232)\end{array}$ & $0.66313^{* *}(0.0172)$ \\
WINE-Index & $0.55323^{* *}$ & $0.6454^{* *}(0.0134)$ \\
\hline
\end{tabular}

Source: Hellenic Republic Ministry of Rural Development and Food (2017); Ministerio de Agricultura Española (2017); Ministero Delle Politiche Agricole Alimentari e Forestali (2017); Ministere de'l Agriculture de'l Agroalimentaire (2017); Ministro de Agricultura Chileno (2017); Ministerio de Agricultura, Ganaderia, y Pesca Argentino (2017); The Wine Institute (2017); World Trade Organization (2017).

Note: The parentheses show the P-value; ${ }^{\star} /$ Indicates $10 \%$ level of significance; ${ }^{\star *} /$ Indicates $5 \%$ level of significance; $* * *$ Indicates $1 \%$ level of significance 


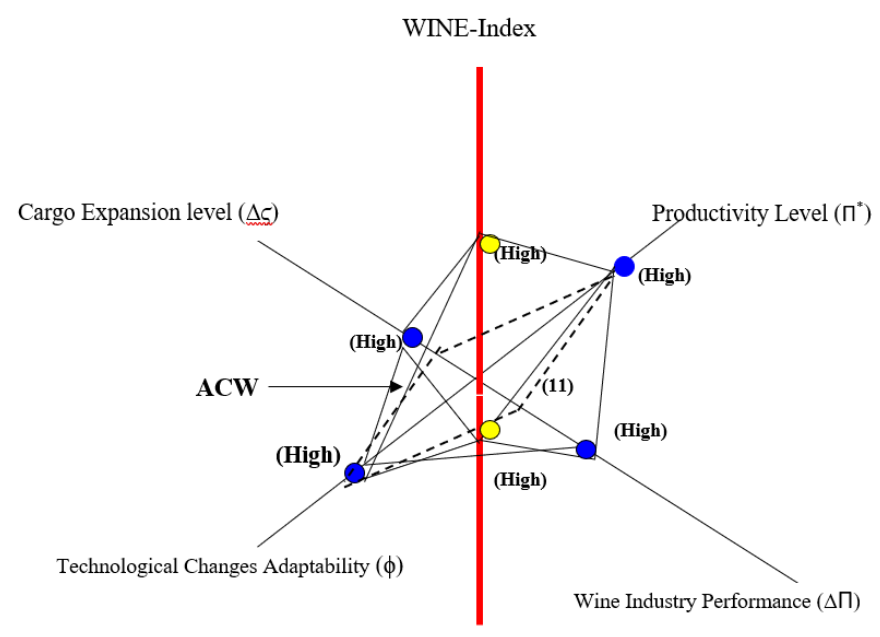

Figure 4. Wine industry growth diamond for France.

Source: Hellenic Republic Ministry of Rural Development and Food (2017); Ministerio de Agricultura Española (2017); Ministero Delle Politiche Agricole Alimentari e Forestali (2017); Ministere de'l Agriculture de'l Agroalimentaire (2017); Ministro de Agricultura Chileno (2017); Ministerio de Agricultura, Ganaderia, y Pesca Argentino (2017); The Wine Institute (2017); World Trade Organization (2017).

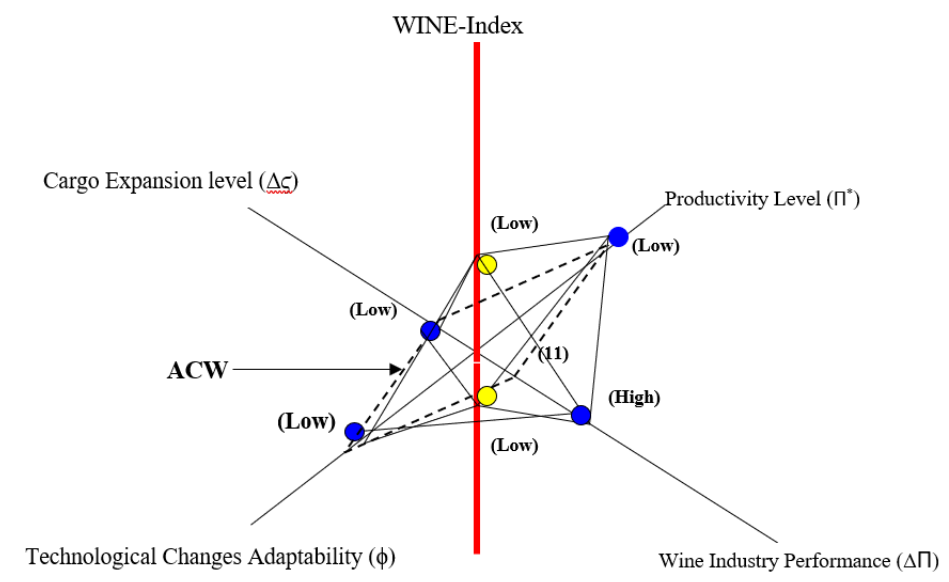

Figure 5. Wine industry growth diamond for Argentina.

Source: Hellenic Republic Ministry of Rural Development and Food (2017); Ministerio de Agricultura Española (2017); Ministero Delle Politiche Agricole Alimentari e Forestali (2017); Ministere de'l Agriculture de'l Agroalimentaire (2017); Ministro de Agricultura Chileno (2017); Ministerio de Agricultura, Ganaderia, y Pesca Argentino (2017); The Wine Institute (2017); World Trade Organization (2017). 


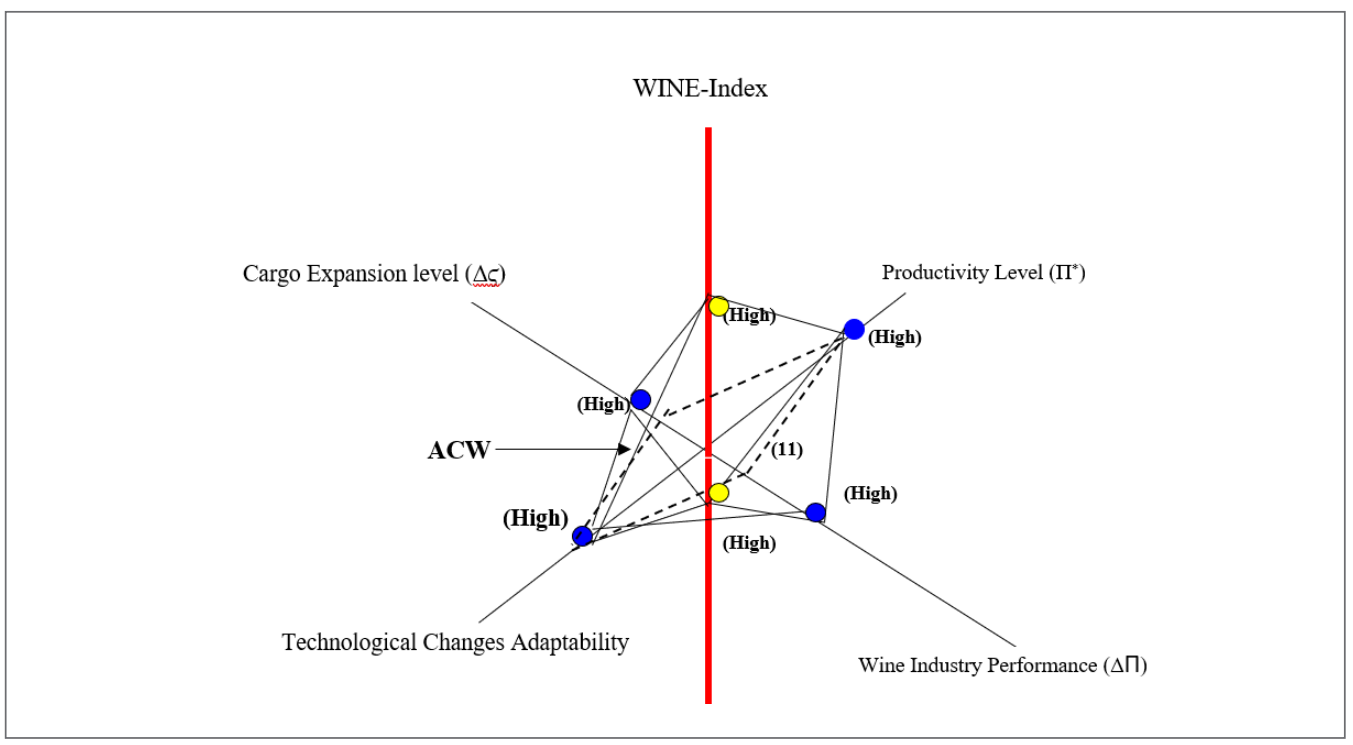

Figure 6. Wine industry growth diamond for Italy.

Source: Hellenic Republic Ministry of Rural Development and Food (2017); Ministerio de Agricultura Española (2017); Ministero Delle Politiche Agricole Alimentari e Forestali (2017); Ministere de'l Agriculture de'l Agroalimentaire (2017); Ministro de Agricultura Chileno (2017); Ministerio de Agricultura, Ganaderia, y Pesca Argentino (2017); The Wine Institute (2017); World Trade Organization (2017).

Model in simulation for year 1970 and simulation for year 2010 show the existence of a positive longrun elasticity from both variables namely the wine industry performance rate $(\Delta \Pi)$ and the wine industry productivity rate $\left(\Pi^{*}\right)$. Hence, it means that the WINE-Index is highly affected by any change from the wine industry performance rate $(\Delta \Pi)$; the wine cargo expansion rate $(\Delta \varsigma)$; the technological changes adaptability rate $(\phi)$; the wine industry productivity rate $\left(\Pi^{*}\right)$ anytime and anywhere. Therefore, we need to take into consideration a proper technology and soft technology (workers high qualified) to prepare for potential strong changes of production cost and logistic platforms in the medium and long-run.

\section{Conclusions}

In this study, we incorporate wine industry performance, productivity level, wine cargo expansion, and adaptability of wine industry to technological change adaptability to evaluate wine industry performance. The wine industry performance evaluation model (WINE-Model) was proposed to evaluate how the above factors can directly affect the productivity rate and performance of the wine industry. The objective is to offer policy makers and researchers a different, more dynamic perspective in assessing the effect of changing factors such as international trade trends, technology shocks, or competition in evaluating the wine industry performance.

The versatility and adaptability of the WINE-Model is such that it can be applied to any production unit or a group of economic activity. It is not constrained by geographical area or development stage of the industry. It is thus simple, flexible, and versatile. In an era of globalization where structural changes take place in short cycles and production units constantly change location, the main advantage of the WINEModel is the ability to capture and measure wine 
industry performance from a dynamic viewpoint.

The main conclusion from our analysis is that the key to maximizing wine industry productivity rate (Crozet, Head, and Mayer, 2012) is efficient coordination of wine market performance rate, wine industry productivity rate, rapid expansion of wine cargo, and adaptability of the wine industry to technological shocks. The second main finding is that wine industry productivity rate depends on how well human capital factor can adapt to new technologies and production systems.

\section{References}

Balakrishnan, P. \& Pushpangadan, K. (1994). Total factor-productivity growth in manufacturing industry: A fresh look. Economic and Political Weekly, 29(31), 2028-2035.

Crozet, M., Head, K., \& Mayer, T. (2012). Quality sorting and trade: Firm-level evidence for French wine. The Review of Economic Studies, 79(2), 609644.

Olmos, M. F. (2010). The performance implications of "grow or buy" decisions in the wine industry. Food Policy, 35(3), 256-264.

Garcia, F. A., Marchetta, M. G., Camargo, M., Morel, L., \& Forradellas, R. Q. (2012). A framework for measuring logistics performance in the wine industry. International Journal of Production Economics, 135(1), 284-298.

Hellenic Republic Ministry of Rural Development and Food. (2017, January 20). Wine statistics section. http://www.minagric.gr/index.php/en/

Mariani, A., Pomarici, E., \& Boatto, V. (2012). The international wine trade: Recent trends and critical issues. Wine Economics and Policy, 1(1), 24-40.

Ministerio de Agricultura Española [Spanish Ministry of Agriculture] (2017, January 31). Wine statistics section. http://www.magrama.gob.es/es/

Ministero Delle Politiche Agricole Alimentari e Forestali. [Ministry of agriculture, food, and forest policy] (2017, January 25). Wine statistics section. http://www.politicheagricole.it/flex/cm/ pages/ServeBLOB.php/L/IT/IDPagina/202

Ministere de'l Agriculture de'l Agroalimentaire [Ministry of Agriculture and Agro-Food] (2017, May 1). Wine statistics section. http://agriculture.gouv. $\mathrm{fr} /$

Ministro de Agricultura Chileno [Chilean Ministry of Agriculture]. (2017, May 25). Wine statistics section. http://www.minagri.gob.cl/
Ministerio de Agricultura, Ganaderia, y Pesca Argentino [Argentinean Ministry of Agriculture, Cattle's, and Fishing]. (2017, June 25). Wine statistics section. http://www.minagri.gob.ar/site/index.php

Estrada, M. A. R., \& Yap, S. F. (2006). The openness growth monitoring model (OGM-Model). Journal of Policy Modeling, 28(3), 235-246.

Estrada, M. A. R. (2011). Policy modeling: Definition, classification and evaluation. Journal of Policy Modeling, 33(4), 523-536.

Estrada, M. A. R., \& Park, D. (2018). The past, present and future of policy modeling. Journal of Policy Modeling, 40(1), 1-15.

The Wine Institute. (2017, July 30). Wine statistics section. http://www.wineinstitute.org/resources/ statistics

World Trade Organization. (2017, September 15). Wine statistics section. www.wto.org 